\title{
NEW-TYPE INTENSIVE RURAL SETTLEMENTS IN CHINA BASED ON THE UNIFIED AND SELF-CONSTRUCTION MECHANISMS OF SPATIAL ORGANIZATION
}

\author{
JIANG WANG ${ }^{1,2}$, JI-LONG ZHAO ${ }^{1,2}$, TIAN-YU WU ${ }^{3} \&$ LU-KUN TANG ${ }^{2}$ \\ ${ }^{1}$ Shandong Co-Innovation Center of Green Building, Jinan, China. \\ ${ }^{2}$ School of Architecture and Urban Planning, Shandong Jianzhu University, Jinan, China. \\ ${ }^{3}$ Yellow River Shandong Survey and Design Research Institute, Jinan, China.
}

\begin{abstract}
The spatially intensive development of rural settlements has become an important power, which is driving the current new-type urbanization in China. However, affected by the lack of guidance and control of space planning and in the space for self-construction, this process has always been facing the risk of being short of spatial characteristics. To solve the conflict between unified-construction and selfconstruction, this paper studies the method to design the intensive rural settlement (IRS) suitable for China by taking Yuezi Village as an example, and proposes the "main board + plug-ins" construction system (MPCS), with the hope of guiding the transformation from traditional rural settlements (TRS) to IRS. To better study the 4-layer rural spatial structure of house-neighborhood-block-settlement, the spatial-temporal evolution of the MPCS was explored with spatial hetero-organization and self-organization as the theoretical support. 1. Unified-construction unit and self-construction unit are defined to constitute the basic coordinated units of MPCS. 2. The simulation rules were mainly defined, making the model able to guarantee villagers' basic living needs and further needs. 3. The logic of transforming rural housing's spatial prototype to an evolutionary model was studied, and computer programming was mainly used to study the control of spatial evolution.
\end{abstract}

Keywords: construction system, evolutionary model, generative design, intensive rural settlement, simulation rules, unified and self-mechanisms.

\section{INTRODUCTION}

TRSs in China have been experiencing rapid new-type urbanization. To all-roundly improve the living environment and basic service facilities in TRS, in 2006, the Central Government of China laid down a series of political and socio-economic implications of the policy to guide the transformation from TRS to new-type rural communities [1]. The Government planned to build rural settlements into well-organized social life communities featuring perfect services, civility and harmony [2] in accordance with the standards for building urban communities. Meanwhile, they also aimed to preserve farmland and restrict changes in land use, allowed some jurisdictions to reclaim rural houses as farmland in exchange for the right to construct on farmland at the urban fringe. In recent years, most of local governments in China have adopted almost the same programs in carrying out the above policy; namely, they relocate and consolidate two or more natural villages or administrative villages into one in a given time, and establish a new centralized residence mode, service and management mode, and industrial pattern by unified planning and construction. These programs had to move villagers from their farmland, and have led to the reconstruction of thousands of villages as high-density and concentrated rural communities, relocating millions of villagers [3]. In the circumstances, the Government hope that the planning and construction of new-type rural communities can become the most important factor promoting the balance between urban and rural development [4]. Issues 
on new-type rural communities have been getting the attention of more and more scholars [5]. However, until recently, the majority of studies focused on rural depopulation, land use efficiency, infrastructure construction, and service facility of rural areas [6]. Such studies on technical tactics of village planning are relatively macroscopic and qualitative, hard to form a series of sustainable spatial codes to guide planning a specific project of IRS [7].

As a result, some spatial problems have arisen in the process of constructing some of the IRSs in China.

- Some rural communities are constructed by urban-style planning, blindly copying the experience in constructing urban communities to meet deadlines, and thus the buildings, featuring obvious "city orientation" and rootlessness, are not in harmony with the process of urbanization and modernization. There is serious homogenization that is reflected in blurring the urban-rural boundary and making the styles of all villages similar.

- Landless villagers are forced to move to storied buildings collectively. Though the quality and comfort level of their new living space are improved, they lose the land-use right that they have enjoyed for most of their lives; in other words, the common activities that they have been accustomed to, such as breeding, planting, building, and doing business, are limited.

- Because the new-type rural communities fail to keep the traditional dwelling environment featuring the integration of production, living, and ecology, they could be no longer the spatial-temporal carrier for studying the sustainable design of rural settlements with their traditional styles and features [8].

Apart from the above-mentioned problems, China's TRSs, in which agriculture is generally the major economic activity, were spontaneously formed in the long process of production and living. Because they have the characteristics of a certain area, common bond, social communication, identity consciousness, they are regarded as the oldest social communities in the primitive form in human history [9]. It also should be noted that, generally speaking, villagers in TRSs would first build the principal house on the house site and then add other buildings as needed. Villagers' actual needs are the source power driving the development of rural space [10], and there are mainly three needs: firstly, with the increase of family members, the living space needs to be expanded; secondly, limited by the financial strength of a family, the construction needs to be carried out in stages; thirdly, functional space needs to be increased and construction should be carried out as needed. Generally, villagers build their houses independently by using traditional techniques without expert intervention, and personal skills, local traditions, environmental context, and applicable resources are involved in the process [11]. The characteristics of the construction, as defined by Coria and Cantacuzino [12], include addibility, diversity, participation, income-based classification, equality, openness of space, and dispersion. This manner of self-construction based on individual needs is referred to as informality academically, and the space created by this construction is thus called informal space. Compared to the formal space as set out in clear official plans, informal space refers to the phenomenon of multilevel and complex settlement space spontaneously formed by projecting members' self-construction into material space. There are two attitudes towards this kind of space in academic circles: it is good for the organic organization; it is bad for the disorderly construction. It thus seems that the rural reconstruction of unified planning and 
construction, representing obvious official opinion, is generally in opposition to the spontaneous development of TRS. The worst defect of unified-construction lies in the neglect of villagers' actual demand, which is mainly reflected in the following three conditions: firstly, if the building area exceeds the actual demand, there will be surplus unused rooms; secondly, if the building area fails to meet the actual demand, there will be no chance to expand the space; thirdly, if the building area just meets the actual demand, it will be hard to develop the functions of the space other than living, such as production and management.

To solve the above problems, this paper studies the method to design the IRH suitable for China's actual conditions by taking Yuezi Village, Zhangqiu City as an example. The design should not only be different in construction pattern from both the spontaneously formed TRS and new-type rural communities established by unified planning and construction, but also adopt their advantages in meeting various demands and improving living quality, and avoid their disadvantages of disorderly construction and extensive one-time forming. Therefore, the key to solving the problems lies in the establishment of the rural settlement design and research system, which considers both unified planning and construction and self-construction.

\section{DESIGN ANALYSIS}

\subsection{Location}

The overall arrangement of Yuezi Village has the typical spatial feature of rural settlements in North China - low rise and high density. Most of the residences in the village were built at the foot of hills based on the specific landform and circumstances. Tier upon tier of buildings are generally facing south, except for some that are forced by the shape of hills to face at the direction with an angle off the due south. The building materials are mainly stones, mud bricks, and other traditional materials, and modern building materials are also used for new buildings or reconstruction. The residences have poor quality and are for long years out of repair. The buildings, mainly single-story, have an average area of the house site of about $220 \mathrm{~m}^{2}$ and an average building area of about $110 \mathrm{~m}^{2}$. The village, consisting of 202 families and 709 residents in total, is economically backward with low per capita income; the annual average income of villagers engaged in agriculture throughout the year is about 5,000 6,000 yuan, and that of migrant workers is about 20,000 yuan.

\subsection{Development needs}

To fulfil the general development target of Yuezi Village, which is to take agriculture and tourism as economic growth engines and build it into a sustainable village featuring the integration of production, living, and ecology, we mainly adopt three strategies, subject to the limitation on the village's overall spatial structure: firstly, retain the residences in the village with a good look; secondly, reconstruct the residences that can be changed for the better through partial repair and reinforcement; thirdly, dismantle the buildings whose appearance is very poor and discordant with the village's overall scene, or whose function should be changed. At present, there are 42 households in all that meet the conditions for relocation to IRS, including 5 households enjoying the minimum living guarantee, 25 households enjoying the five guarantees, 10 moderately wealthy households, and 2 very wealthy households. 


\subsection{Site analysis}

According to the vision plan, the above-mentioned 42 households will be moved to the northeast of the original location of the village and collectively settled in the new village that is going to be built near the entrance to the village and next to the location for a planned biogas plant. The construction site is $280 \mathrm{~m}$ from east to west and $55 \mathrm{~m}$ from south to north, covering an area of 1.54 hectares. Adjoining a gentle slope to the south and a river to the north, the site has a generally flat terrain high in the south and low in the north, outspreading along the river in an east-west direction.

\subsection{Design requirements}

After many discussions, the village committee and the villagers agreed with the following four requirements proposed by us. Firstly, devices for solar power, biogas, and spring water and other facilities shall be installed in every household in the new village. Secondly, the new village shall be with the 4-layer spatial structure of the house-neighborhood-block-settlement. Thirdly, the number per household is from 2 to 5 , so the 2 bedrooms for every household are just met the requirements of one household with an older couple and a young couple with a baby. Fourthly, because the households are greatly different from each other in their current housing conditions and there are functional needs in addition to the need for a dwelling house, we define the maximum legal area of a villager's house site and the minimum building area required for basic living as the economic and technical indicators, to achieve the balance by paying compensation for the difference and thus make sure both the rich and poor can bear and benefit from this arrangement. Finally, we will provide households with guidance on selfconstruction, and they can improve their housing conditions by themselves according to the actual needs of all sides.

In accordance with the Technical Guidance on Making Construction Plans for Villages in Shandong Province (Guidance), the per capita construction land area shall be $\leq 90 \mathrm{~m}^{2}$; the house site area per household shall be $\leq 166 \mathrm{~m}^{2}$ (because the terrain slopes gently, the standard for settlements on the plain is applied); and the building density (BD) on the house site of each household shall be $\leq 70 \%$. In accordance with the requirements that the floor area ratio and building area per household shall be $\geq 0.5$ and $\leq 250 \mathrm{~m}^{2}$ respectively, the minimum building area per household is set as $83 \mathrm{~m}^{2}$ (if land shortage, a downward fluctuation of up to $10 \mathrm{~m}^{2}$ is allowable). Two-storied buildings should be given priority, and the story number should not exceed 3 .

\subsection{Draft planning}

Firstly, the length-width ratio of the house site in the new village should be determined on the premise of guaranteeing the intensive utilization of land. By referring to the ratio of existing rural residences and modern townhouses and carefully comparing the cases with different ratios, we reached the conclusion that it will be easier to establish a courtyard house on the form with larger width, especially with its length-to-width ratio nearing 1, while building a L-shaped house on a house site with small width or with a length-to-width ratio $\geq 1.5$ can make use of the land more fully and effectively. Secondly, the module of the house site was set as $1.5 \mathrm{~m}$ for the convenience of limiting the width of the small room and the size of other functional rooms. Thirdly, according to the boundary line of the construction site for the new 
village and the requirement that the house site area per household shall be $\leq 166 \mathrm{~m}^{2}$, the length and width of the house site were set as $15 \mathrm{~m}$ and $10.5 \mathrm{~m}$ respectively. Finally, the draft planning for the new village was made by taking the house site as a unit and a few households $(\leq 6)$ as a group.

\section{THEORETICAL MODEL ANALYSIS}

\subsection{Theoretical model}

Hetero-organization and self-organization, successively proposed by the German philosopher, Kant, and the German physicist, Haken, from different angles, are the two terms for explaining the concept of organization. Hetero-organizations are formed under external directives, while self-organizations are formed automatically without external directives by members complying with some rules of tacit understanding and doing their duties coordinately. The unity of the opposites has been gradually regarded as the dynamic mechanism of the construction system's spatial-temporal evolution, and turned out to be the external social logic and internal spatial logic of spatial changes [13]. It's worth noting that various kinds of studies on the evolutionary mechanism of human settlements is being deepened constantly with the large-scale, standardized, and fast growth of historic city hetero-organizations, the constant loss of the diversity of spatial awareness, and the deeper cognition of the connotation of space in various subjects.

Among the studies on top-down or bottom-up urban planning, some scholars hold the opinion that, with the many-faceted development of society and the collapse of the orderbased centrally planned economy, there has been an urgent need to update the old top-down planning concept, analyze and manage the complex city system in a bottom-up manner, and mediate the theoretic disputes and realistic contradictions on what can be planned and what cannot be planned [14]. They pointed out that a complete residential spatial organization should contain both an endogenous self-organization, which represents the force promoting spatial development and systematic evolution, and an exogenous auxiliary hetero-organization. The intermediate and micro-level mechanism of organizing human residential space can be seen in the studies on unified-construction and self-construction in architecture, such as the Elemental's Quinta Monroy in Iquique designed by Alejandro Aravena [15], the New Gourna Village designed by Hassan Fathy [16] and the self-help strategies proposed by Turner [17]. Friedman [18], in his study on mobile architecture and adaptation, investigated the small-scale self-generated units, which are separated from the whole and made to adapt and adjust in the regular and rigid structural support, through the phenomenon of critical group-size, and thus guided members to conduct self-construction. Habraken [19], in his study of support (S) and infill (I), pointed out that the frame-infilled open housing system and support technology (SAR) can disperse the power distribution in the construction process and guide the changes of functions for adaptation. Rapopport [20], in his study of model + adjustment, sought for the model in traditional rural life and obtained new spatial form after suitable adjustments.

It is thus obvious that the theoretical studies on the space with collaboratively symbiotic hetero-organization and self-organization to resist the conventional or previously given forms or models have gradually become an important ideological trend to develop the traditional human residential space. 


\subsection{Methods}

The main methods are as follows. Firstly, according to a literature review, design analysis and the Guidance, all possible configurations of houses should be designed in advance in the form of diagrams, including floor plan and axonometric drawings. Secondly, the rules of unifiedconstruction and self-construction are all defined in terms of relative coordinates, to ensure the spatial-temporal evolution of houses can be clearly expressed in coordinates. Thirdly, the rules are encoded into computer programs using the Python programming language to conduct computer simulation. Finally, the generated simulation results are used to complete generative design by CAD and Google sketchUp.

\subsection{Definition of MPCS}

Based on the above theoretical models, the MPCS is an application solution for the construction of IRH in China. In this system, villagers can participate in the planning and design of a new village. To put it simply, the MPCS refers to the model consisting of "main board + plugins"; $\mathrm{M}$ is short for Main Board, representing the space for unified planning and construction, and $\mathrm{P}$ is short for Plug-ins, representing the space for self-construction. On the basis of planned framework and core space, i.e. the Main Board, villagers are allowed to independently expand the functional space according to their specific needs, i.e., to create the Plug-ins.

The Main Board space, consisting of unified-construction units, is an open spatial structure, formed through unified planning and construction, to which peripheral equipment and functional spaces (Plug-ins or spaces for self-construction) are connected. The unified-construction units (Fig. 1) include not only the rooms to meet basic living needs, including an equipment room, a living room, a kitchen, 2 bedrooms, a rest room, and an indoor stair, but also the structural measures to establish feasible connection with Plug-ins. The "Plug-in" space, consisting of self-built units, is divided into four functions: living space, space for production, space for renting, and space for doing business, according to the villagers' possible needs in the future.
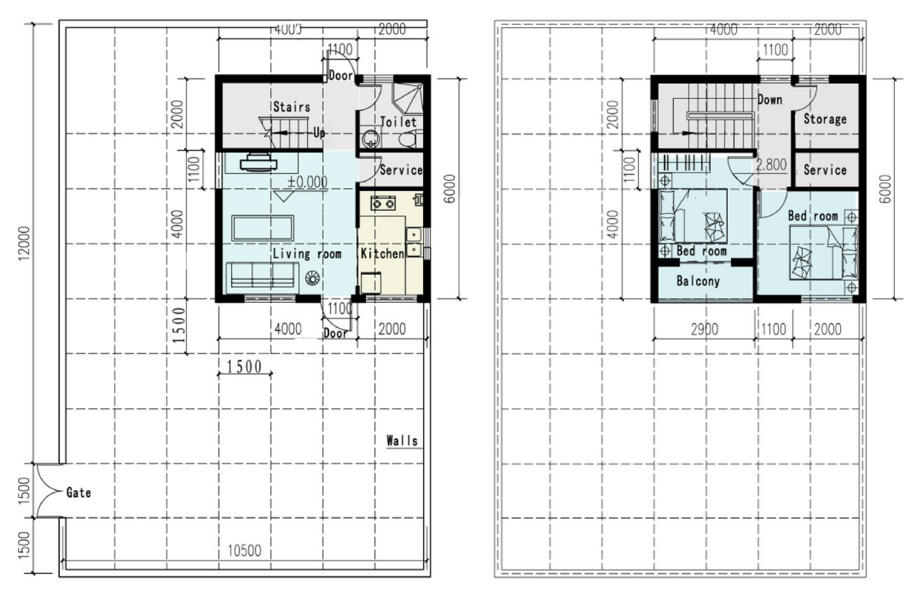

Figure 1: Ground floor plan and second floor plan of the main-board. Source: Author. 


\section{SIMULATION RULES}

\subsection{Design assumptions}

Construction site for the new village. To facilitate programming and computer simulation, the previously made draft plan was simplified and then placed in the orthogonal grid. The principle for planning the multi-functional network is that the convenient connection between the network and the equipment room on the house site should be guaranteed.

Main Board space. Both the width and depth of its plan form were set as $6 \mathrm{~m}$ after comparative analysis, and thus the total building area for two stories is $72 \mathrm{~m}^{2}$ (the total area including the area of external walls is $76.88 \mathrm{~m}^{2}$ ). The location of the equipment room shall be determined in the plane.

Plug-in space. As the biggest variable in computer simulation, the building area and floor area corresponding to the Plug-in space shall be in accordance with the Guidance.

\subsection{Determine the location of unified-construction units}

According to the relation between the "Main Board" and the house site, we defined 4 states for the Main Board. If taking the point at the top right corner of the house site as the origin of coordinates $(0,0)$, the coordinate of the point at the top right corner of the Main Board could be $(0,0),(0,1),(0,2)$, and $(0,3)$.

\subsection{Diversify the forms of unified-construction units}

On the premise of guaranteeing the wholeness of the Main Board, extend the sloping roof on the Main Board to the east or west (overhanging) for 3 cells, and thus diversify the forms of the Main Board in the process of visualization. Meanwhile, generate the complete, diversiform, and regular scenes of the new village by inputting the changes of the location of the Main Board in the house site and different states of self-built Plug-ins. The simulation finally proved that the simulated arrangement of the new village could be in harmony with the original settlement. The diversification of the Main Board mainly includes 8 conditions (Fig. 2).

\subsection{Pre-design the possible configurations of self-built units}

For the last diagram in Fig. 2 as an example, according to the function of living, production, commerce and renting, the possible configurations of self-built units should be pre-designed (Fig. 3), to ensure the reliability of the subsequent simulation.
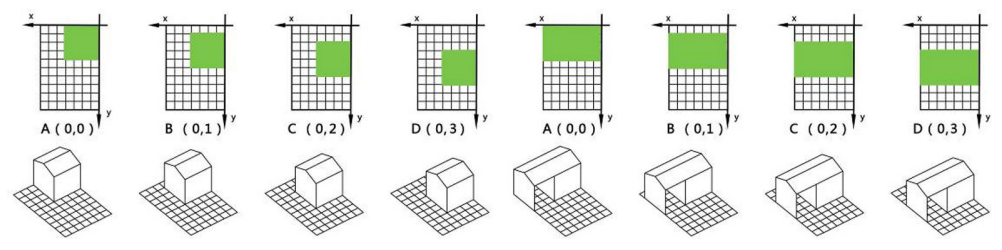

Figure 2: Main-board's location and its different forms. Source: Author. 


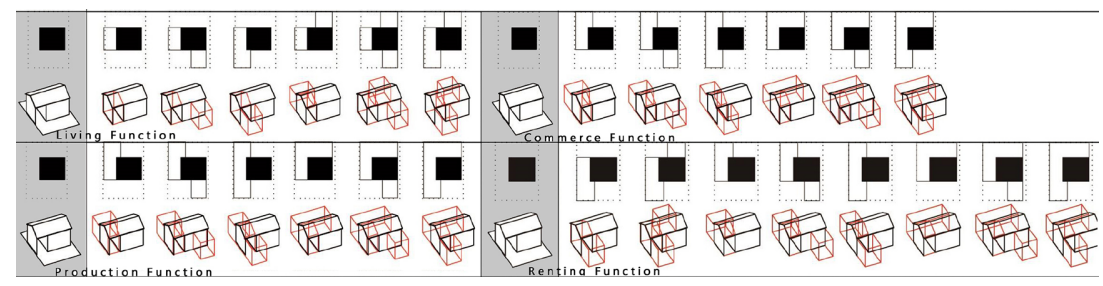

Figure 3: The possibility of self-built units. Source: Author.

\subsection{Limit the scope of self-built units}

- Influence of BD (Fig. 4.1). According to the Guidance, the BD shall be less than 70\%. Therefore, the courtyard of each household shall cover at least 21 cells $\left(1.5^{*} 1.5 \mathrm{~m}\right)$, with a minimum area of $47.25 \mathrm{~m}^{2}$. On the premise of meeting the requirement for BD, the possibilities of courtyard form were studied and analyzed, and then the scope of "Plug-in" buildings were limited according to villagers' actual living and production needs.

- Influence of the daylighting standard. According to the Guidance, there shall be at least one living room or bedroom in a house meeting the standard of 2-hour daylighting on the day of Great Cold (the 24th solar term), and the coefficient of the local buildings insolation interval is 1.3. Considering the simulation of spatial-temporal evolution is multistage, this standard is only applied to two stages: 1, the stage of unified planning and construction, in which the south Main Board space shall not shadow the rooms facing the south located in the north Main Board space (Fig. 4.2); 2, the initial stage of selfconstruction, in which the Plug-in space on the south house site shall not shadow the north Main Board space (Fig. 4.3). There is a special case that, if the Plug-in space shadows the Main Board space on the same house site, the influence of the south Plug-in space on the Main Board space on the north house site can be ignored.

- Influence of compound functions. If a Plug-in space is used for living, the easy communication, daylighting, neighborhood, life convenience, and other factors involving the relations between the Main Board space and Plug-in space shall be considered. If a Plug-in space is used for planting, breeding, or other production, the location of the space shall be relatively isolated from the Main Board space, so as to reduce the influence; the space's influence on the Main Board spaces on the neighboring house sites shall be considered as well, and a suitable spacing shall be kept between the two spaces. If a Plug-in space

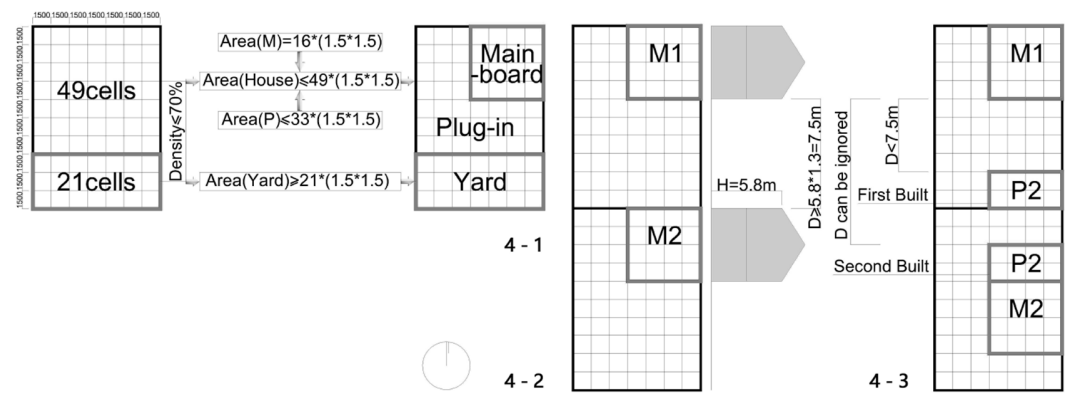

Figure 4: Influence of BD and the daylighting standard. Source: Author. 
is used for commerce, the effect of "golden corners and silver edges" on obtaining maximum benefit shall be considered, and the relative independence between the commercial space and living space shall be considered as well to lower the former's interference to the latter. If a Plug-in space is used for renting, the independence and convenience between the Main Board space and Plug-in space shall be considered.

- Influence of streets. The simplified pattern of the new village presents a linear relation. There are about 2-3 rows in the north-south direction. The groups are mainly in the forms of three rows and two columns, two rows and two columns, and two rows and one column. The groups are connected by $6 \mathrm{~m}$-wide ring roads, and each pair of the groups is connected by a $4.5 \mathrm{~m}$-wide longitudinal roadway (Fig. 5.1).

\section{SPATIAL EVOLUTION PROCESS}

Defining the rules of unified and self-construction for a group of rural housing is the premise of studying the logic of transforming the rural housing's spatial prototype to an evolutionary model. After defining the rules, we designed suitable algorithms and used Python language to turn the rules into computer programs, which were used to simulate the spatial-temporal evolution of unified and self-construction and monitor the changes of BD on each house site in real time (Fig. 5). This computer program primarily consists of the following functions: unifiedCons (homestead, location, area), which takes the homestead of a house, the location and area of the unified-constuction units as input, and output the unified-constuction results; selfCons (homestead, constraints), which take the homestead of a house and constraints like maximum plot ratio as input and output the self-constuction results. The selfCons (homestead, constraints) function can be further decomposed into several sub-functions, including extend (direction) that performs one step self-construction along the given direction, and checkConsistency (constrains) that checks whether any of the specified constraints has been violated, etc. Finally, the obtained design scheme with the dynamic evolution process was uploaded to the CAD software in the form of CAD script automatically created by the computer program, so as to realize visualization and make further improvements.

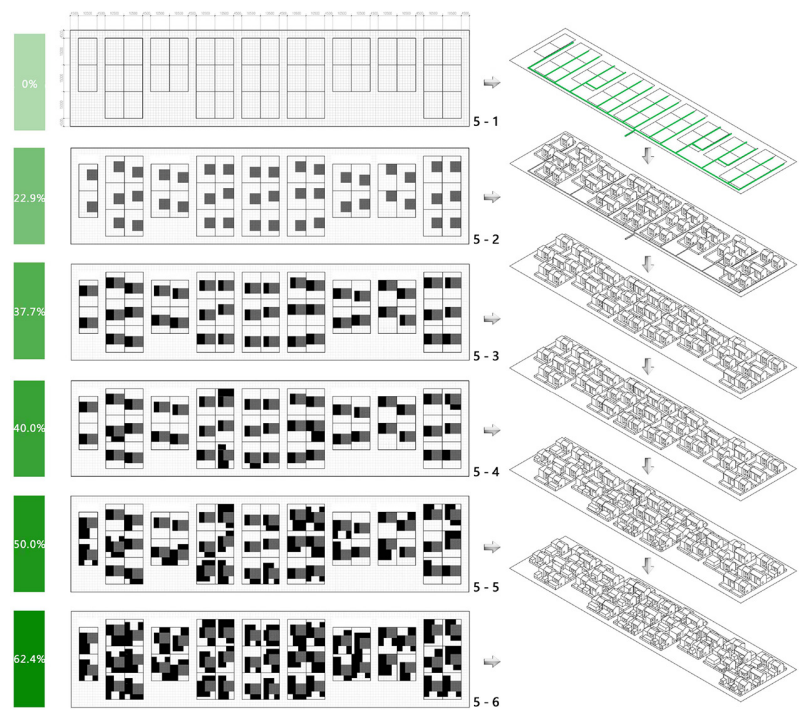

Figure 5: The process of spatial evolution and visualization. Source: Author. 


\subsection{Primary stage}

This stage refers to the unified planning stage for the Main Board space (Fig. 5.2). The planned Main Board space can meet each household's most basic needs for production and living. The $\mathrm{BD}$ in the primary stage is $22.9 \%$, and the floor area ratio is 0.5 , indicating the buildings are in a loose state, and there is a great change for them to grow.

\subsection{Growth stage}

After the Main Board space is fixed, the self-construction buildings begin to thrive in the form of Plug-ins. Firstly, the self-construction is guided to concentrate on the left side or right side of the Main Board (Fig. 5.3); then, the BD rises to $37.7 \%$ and the floor area ratio rises to 0.7. After that, the self-construction will be carried out randomly, but the above Guidance shall be followed to form the L-shaped or U-shaped pattern. The building densities of the two patterns are $40 \%$ (Fig. 5.4) and 50\% (Fig. 5.5) respectively and the difference is used to distinguish the spatial changes.

\subsection{Saturation stage}

When the BD reaches the saturation state (Fig. 5.6), the self-construction on the house sites will be forbidden. At the moment, the buildings of MPCS in this stage can meet villagers' various needs for living, doing business, and producing.

\section{CONCLUSION}

In conclusion, the MPCS featuring the coordinate symbiosis of unified and self-construction space can play a significant role in connecting rural settlement update with rural housing innovations and constructing sustainable IRS. Firstly, the spontaneous spatial forms of the original rural settlement were picked out and sorted, so as to reuse the field elements in the original space. Secondly, a computer simulation was used to realize the coordinate symbiosis of planned space and self-construction space in the spatial development of the new-type IRS. Finally, the support technology was applied to realize the "regeneration of adaptability" of related proper technical measures in the spontaneous space and the transformation to selfconstruction space. Thus, this MPCS can guarantee both the unified-construction by governments and the self-construction by villagers. Establishing the system for creating selfconstruction space in new IRS can not only guarantee the space planned by governments, designers, and investors to be developed, but also turn the disorderly spontaneous construction into orderly self-construction within the planning space. However, many efforts have to be done in the future in this research topic. One of the possible further study is that some secondary elements in theoretical model such as decorative elements, topography, regional habits, etc., have been simplified, causing the result cannot completely reflect the spatialtemporal evolution of the IRS. And also the floor area ratio is not directly encoded in computer programs, so the simulation result only shows 2-dimensional plane, and 3-dimensional effect of the houses and the IRS have to be generated by CAD and Google sketchUp.

\section{ACKNOWLEDGEMENTS}

The research was financially supported by the National Natural Science Foundation of China (Grant No. 51408343, Grant No. 51378301), China Scholarship Council (Grant No. 
201305870009), Shandong Co-innovation Center of Green Building Found (Grant No. LSXT201503), Shandong Provincial Natural Science Found, China (Grant No. ZR2013EEQ017, Grant No. ZR2012EEM008). The authors would like to thank PHD Ke-Yang Zhang (University of Illinois at Urbana-Champaign) and the anonymous reviews for their comments and suggestions.

\section{REFERENCES}

[1] Wang, J., Yang, N. \& Qiu, S., Research of spatial construction strategy in Chinese new rural community. Journal of Landscape Research, 4(7), pp. 33-34, 2012.

[2] China, G., Decision concerning some questions about the construction of harmonious socialist society. Journey of Qiushi, 20, pp. 3-12, 2006.

[3] Ong, L.H., State-led urbanization in China: skyscrapers, land revenue and "Concentrated Villages". The China Quarterly, 217, pp. 62-79, 2014. https:/doi.org/10.1017/S0305741014000010

[4] David, B., Urban planning goes rural: conceptualising the "New Village". China Perspectives, 3, pp. 53-62, 2013.

[5] Zhou, G., He, Y., Tang, C., Yu, T., Xiao, G. \& Zhong, T., Dynamic mechanism and present situation of rural settlement evolution in China. Journal of Geographical Sciences, 23(3), pp. 513-524, 2013. https:/doi.org/10.1007/s11442-013-1025-7

[6] Chen, Y., Lü, B. \& Chen, R., Evaluating the life satisfaction of peasants in concentrated residential areas of Nanjing, China: A fuzzy approach. Habitat International, 53, pp. 556-568, 2016.

https:/doi.org/10.1016/j.habitatint.2016.01.002

[7] Dandong, G. \& Chen, H., Technical tactics and process model of village planning in the perspective of countryside. City Planning Review, 34(6), pp. 55-59, 2010.

[8] Fang, Y. \& Liu, J., Cultural landscape evolution of traditional agricultural villages in North China: case of Qianzhai Village in Shandong province. Chinese Geographical Science, 18(4), pp. 308-315, 2008. https:/doi.org/10.1007/s11769-008-0308-X

[9] Sun, Y., Chen, T. \& Wang, Y., Progress and prospects in research of the traditional rural cultural landscape. Progress in Geography, 27(6), pp. 90-96, 2008.

[10] Rudofsky, B., Architecture Without Architects: A Short Introduction to Non-Pedigreed Architecture, UNM Press, 1964.

[11] Brown, R., Designing differently: The self-build home. Journal of Design History, 21(4), pp. 359-370, 2008. https:/doi.org/10.1093/jdh/epn033

[12] Correa, C. \& Cantacuzino, S., Charles Correa (Vol. 1), Concept Media, 1984.

[13] Hillier, B., Space is the Machine: A Configurational Theory of Architecture, Cambridge University Press, 2007.

[14] Portugali, J., Self-Organization and the City, Springer Science \& Business Media: Berlin, 1999.

[15] Rangel, B., Abrantes, V., Alves, F.B. \& Faria, A., Integrated team for progressive house in the XXI century. International Journal for housing Science, 36(3), pp. 150-161, 2012.

[16] Elshahed, M. \& Hamid, A., Hassan Fathy and Continuity in Islamic Arts and Architecture: The Birth of a New Modern, American University in Cairo Press: New York, 2013. 
[17] Turner, J., The squatter settlement: an architecture that works. Architectural Design, 38(4), pp. 357-360, 1968.

[18] Friedman, Y., Trobaugh, W. \& Roullier, E., Pro domo. Actar, 2006.

[19] Habraken, N.J., Variations: the Systematic Design of Supports, Laboratory of Architecture and Planning at MIT: Boston, 1976.

[20] Rapoport, A., House Form and Culture, Englewood cliffs: New Jersey, 1969. 